\title{
Cracking the Cell Death Code
}

\author{
Carla V. Rothlin ${ }^{1,2,4}$ and Sourav Ghosh ${ }^{2,3,4}$ \\ ${ }^{1}$ Department of Immunobiology, School of Medicine, Yale University, New Haven, Connecticut 06520, USA \\ ${ }^{2}$ Department of Pharmacology, School of Medicine, Yale University, New Haven, Connecticut 06520, USA \\ ${ }^{3}$ Department of Neurology, School of Medicine, Yale University, New Haven, Connecticut 06520, USA \\ Correspondence: carla.rothlin@yale.edu; sourav.ghosh@yale.edu
}

Cell death is an invariant feature throughout our life span, starting with extensive scheduled cell death during morphogenesis and continuing with death under homeostasis in adult tissues. Additionally, cells become victims of accidental, unscheduled death following injury and infection. Cell death in each of these occasions triggers specific and specialized responses in the living cells that surround them or are attracted to the dying/dead cells. These responses sculpt tissues during morphogenesis, replenish lost cells in homeostasis to maintain tissue/system function, and repair damaged tissues after injury. Wherein lies the information that sets in motion the cascade of effector responses culminating in remodeling, renewal, or repair? Here, we attempt to provide a framework for thinking about cell death in terms of the specific effector responses that accompanies various modalities of cell death. We also propose an integrated threefold "cell death code" consisting of information intrinsic to the dying/dead cell, the surroundings of the dying cell, and the identity of the responder.

... Mrityor ma amritam gamaya (Take me from death to beyond death)

\section{- Pavamana Mantra, Brihadaranyaka Upanishad}

$\mathrm{T}^{\mathrm{h}}$ he inevitability of cell death makes a convincing argument for studying it, not for the sake of trying to prevent it, but rather in the context of understanding its significance to life. Although cell death itself is useful, the response of other cells to the dead cell is critical for the life of the organism. The myriad contexts of cell death and the array of specific responses to it remain a great mystery.

\section{EVER PRESENT CELL DEATH}

What should I do and where should I go? A thief has taken hold of my flesh!

For there in my bed-chamber Death dwells, and wherever I turn, there too is Death

$$
\text { -Epic of Gilgamesh, Tablet XI }
$$

Cell death occurs during embryonic development, in adult tissues in homeostasis, as well as in all manners of damage such as sterile injury or infection. The response to cell death in development, homeostasis, and injury is distinct. Sometimes, dead cells are simply shed, but at other

\footnotetext{
${ }^{4}$ These authors contributed equally to this work.

Editors: Kim Newton, James M. Murphy, and Edward A. Miao

Additional Perspectives on Cell Survival and Cell Death available at www.cshperspectives.org

Copyright (C) 2020 Cold Spring Harbor Laboratory Press; all rights reserved; doi: 10.1101/cshperspect.a036343

Cite this article as Cold Spring Harb Perspect Biol 2020;12:a036343
} 
times, dead/dying cells are actively removed. Occasionally, the dead cell makes way to new types of cells. In other instances, a new cell of the same type takes the place of the dead cell. Death may occur in limited numbers and slowly. Replacement may involve counting the number of cells being lost and its coordination with stem cell proliferation and differentiation to replace the lost cells (renewal or compensation). Or, the loss of cells may occur unexpectedly and extensively wherein repair may require the recruitment and concerted function of a large number of cells of different types. The universality and constancy of cell death, along with the existence of a variety of effector responses to cell death that are highly specialized and specific, point to some kind of a biological code. Yet, our comprehension of this code remains extremely limited.

\section{INFORMATION IS ENCODED IN CELL DEATH}

Have you ever wondered if death is the same for all living beings, be they animals, human beings included, or plants, from the grass you walk on to the hundred-meter-tall Sequoiadendron giganteum, will the death that kills a man who knows he's going to die be the same as that of a horse who never will.

\section{-As Intermitencias da Morte (Death with Interruptions), Jose Saramago}

Attempts to categorize cell death, so far, have primarily relied on the molecular mechanism of execution of cell death. Careful dissection of the many ways cells die has culminated in more than 15 types of distinct cell death modalities including, but not limited to, extrinsic apoptosis, intrinsic apoptosis, immunogenic cell death (ICD), autolysis or lysosome-dependent cell death, autophagic cell death, autosis, entosis, ferroptosis, methuosis, mitotic catastrophe, necroptosis, netosis, oncosis, paraptosis, parthanatos, pyroptosis, sarmoptosis, or mitochondrial permeability transition-driven cell death and phagoptosis (Galluzzi et al. 2018). This bewildering array presents a numerical challenge in trying to understand the information encoded in each type of cell death and how that information is extrapolated to impart specificity of effector responses. Even death by a single mechanism can result in vastly different responses by other cells in the tissue. For example, the response to apoptosis could be removal (in development or postnatal neuronal death), renewal (in adult tissue), inflammation and then repair (when there is apoptosis following sterile injury), and inflammation coupled to an adaptive immune response and repair (when for example there is apoptosis of a virally infected cell). Therefore, the execution mechanism, by itself, is likely not sufficient to code for the effector response. Instead, we speculate "Why cells die?" This essentially teleological question is not intended to assign purpose to cell death, but rather to provide a complementary conceptual framework to categorize the basic types of cell death and the consequences of cell death.

\section{WHY CELLS DIE?}

The sorrows of existence, Oh "Ghalib," what is its cure but death

The flame of the lamp burns in all its shades, till morning comes

$$
\begin{aligned}
& \text {-Till Morning Comes, Mirza Asadullah } \\
& \text { Beg Khan "Ghalib" }
\end{aligned}
$$

The simplest context of thinking about cell death is perhaps accidental cell death during an injury. But, cell death also occurs in a programmed manner, not only in homeostasis but also during embryonic development. Below, we follow the chronology of an organism from birth to adulthood in terms of its encounters with cell death and posit why cells die.

\section{Cell Death during Embryogenesis and Postnatal Development}

Extensive cell death is a feature of developmental morphogenesis (Saunders 1966). Cells die to create a new form or function, or eliminate a function. Many cells, such as those of the larval tissue of insects or amphibians, die and are removed to reshape the tissue/organ during metamorphosis (Suzanne and Steller 2013). In humans, interdigital mesenchymal cells die during the seventh and eighth week of gestation (Jordan et al. 2012). Failure to die can manifest 
as developmental abnormalities. For example, syndactyly involves fusion of soft tissues and failure of differentiation between adjacent digits because of the absence of apoptosis in the interdigital mesenchyme (Hernández-Martínez and Covarrubias 2011; Jordan et al. 2012). Up to 50\% of newborn neurons die during embryonic and perinatal brain development in vertebrates (Yeo and Gautier 2004). Children with autism spectrum disorder were reported to have a significantly increased number of neurons in the basal and central nuclei of the amygdala (Avino et al. 2018). The evolutionary benefit of neuronal death is not known, but it may be to insert randomness into what is essentially a programmed and stereotypical developmental pattern. An individual may be born with the same exact number and organization of neurons, yet become distinct as neurons die randomly (as it relates to comparison between individuals). A similar argument can be made for cell death during digit development wherein an invariant, evolutionarily conserved pattern is tinkered with to create new form and function in some species, for example, webbed feet in ducks makes way for toes in chickens (Yokouchi et al. 1996; Zou and Niswander 1996). Cells also die to eliminate a function. A classic example is the elimination of autoreactive $\mathrm{T}$ cells in the thymus (Daley et al. 2017). Here, we propose the term "type I cell death," wherein a cell dies to create a new function or to elimination an existing function (Fig. 1).

Type I death occurs when the cells receive specific instruction to do so. This instruction may come as the disappearance of a signal such as growth factor depletion or loss of substrate attachment (anoikis), or through the appearance of a specific factor such as signal through the Fas receptor. The molecular mechanism of execution is apoptosis-both caspase8-dependent cell-extrinsic apoptosis and cas-

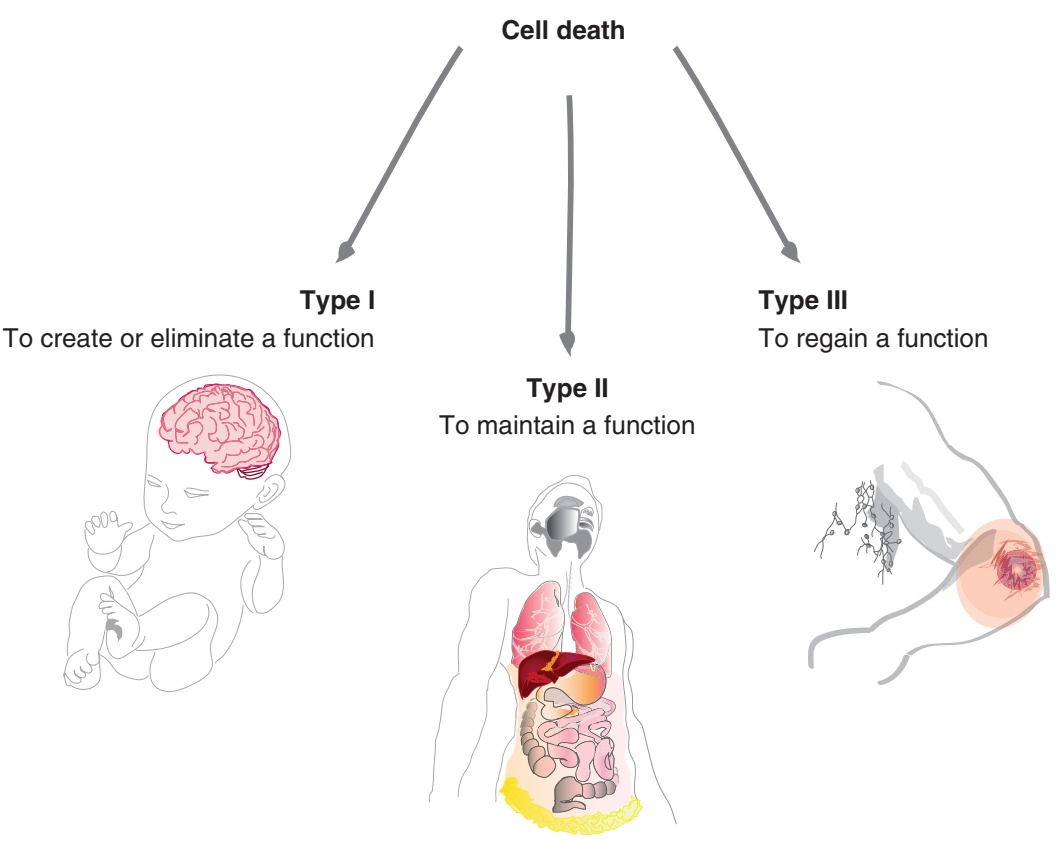

Figure 1. Classification of cell death based on associated outcomes. Cell death associated with the creation or elimination of a function is defined as type I. An example is represented by the cell death associated with embryonic and perinatal brain development. Type II cell death defines the demise of cells associated with homeostatic renewal of tissues in adulthood. This is exemplified by cell death associated with replenishment of adult organs such as the intestine. Unscheduled cell death is defined as type III cell death and is associated with inflammation, immunity (in case of infection), and tissue repair. This is represented in the context of an arm injury. 
pase-9-dependent cell-intrinsic apoptosis. More importantly, type I cell death is associated with a response that is removal only. The process of removal of a dead cell involves its phagocytosis by a responding cell. This specialized phagocytosis is termed "efferocytosis" and the responding cell is termed "efferocyte." There is no need to replace the dying cell with one of its kind. A cell with a different function will take its place.

\section{Cell Death during Tissue/Organ Homeostasis}

Once development is complete, cell death continues to occur in the adult organism. In a healthy adult human being, billions of cells are scheduled to die every day (Arandjelovic and Ravichandran 2015). Cells die to prevent their loss-of-function from endangering or compromising tissue/system function, that is, self-sacrifice for a greater cause. This is perhaps most frequent at the mucosal barriers and other hazardous localizations where cells are more prone to being damaged and therefore at higher risk of progressive deterioration of function. However, this theory should be generally true for other locations. An exception can be logically expected when unique information is stored within the cells or their connections (such as adult neurons) or cells that are tightly coupled for their function (such as cardiomyocytes). Indeed, cell death is observed in most tissues except for the majority of central nervous system (CNS) neurons and cardiomyocytes. In the CNS, cells have been reported to die in specialized areas associated with neurogenesis (Whitman and Greer 2009; Kuhn 2015; Ryu et al. 2016). This type of cell death is an intrinsic part of tissue homeostasis. We propose the term "type II cell death" for the death of a cell during tissue/organ homeostasis, which presumably prevents the loss-of-function/maintains-the-function of the tissue/organ through rejuvenation (Fig. 1).

Type II cell death appears to be a matter of intrinsic choice for the cell. It may be the result of accumulated mutations in its genetic material that may adversely affect its function or duplication. An example would be death caused by DNA-damage or replication errors in cells. The execution mechanism is intrinsic, caspase-9-de- pendent apoptosis. This is also expected to be the primary form of cell death characterized by telomere shortening and mitotic catastrophe such as when cells reach the Hayflick limit. Another form of type II cell death presages loss of metabolic function under conditions of energetic stress. Modalities of cell death in this category may be autophagic cell death, autosis, autolysis, entosis, parthanatos, paraptosis, ferroptosis, or methuosis.

Under homeostatic conditions, cell death requires replacement by another identical cell. Survival depends on the ability to not only remove, but also to replace the dead cells and maintain uninterrupted tissue/organ function. Therefore, type II cell death is associated with proliferation. It is possible that a counting mechanism is encoded in the efferocyte that then communicates this information to the local stem or cycling cell. Either the absence of renewal or ectopic renewal can be problematic-one leads to loss of tissue function, whereas the other may lead to tumorigenesis. We cannot formally rule out the possibility that nearest neighbors play a role in sensing, but not removal, of dead cells and this information accounts for induced proliferation. For example, loss of cell-cell contact with a dead cell might spur cell division and contact-inhibition will serve as the stop signal. Alternatively, the dying cell itself can be the source of a quantum of mitogenic information that directs a defined number of proliferative events (Ryoo et al. 2004). However, the dead cell still needs to be cleared to make space, and failure to clear a dying cell has been reported to prevent cell death (Reddien et al. 2001). Thus, Occam's razor would dictate that the efferocyte simultaneously elaborates signals to replenish. Induction of growth factors coupled to efferocytosis provides important evidence in support of this theory (Morimoto et al. 2001; Golpon et al. 2004).

\section{Cell Death during Injury}

Finally, death may be unscheduled, including both accidental cell death and unscheduled but regulated cell death. Here, cells die as a result of externally caused damage, infection, or because 
of the response to infection. We term this type of unscheduled death as type III cell death (Fig. 1). Examples include nonprogrammed cell death (necrosis) as well as programmed cell death (pyroptosis, necroptosis, and ICD). The response to unscheduled cell death is distinct from that to scheduled cell death. Unscheduled insults lead to a sequence of coordinated mechanisms that can include inflammation and immunity (the latter in case of infected, but not in sterile injury) before culminating, ideally, in tissue regeneration and restoration of lost functions (Medzhitov 2008). The information regarding the cause of cell death is made available to the efferocyte, which in turn, either directly or indirectly through a secondary effector, orchestrates the tissue's response to cell death. Inappropriate or unnecessary responses can manifest as ulcers or fibrosis.

\section{MOLECULAR PATTERNS ASSOCIATED WITH THE DEAD/DYING CELL}

The doctor said: Such-and-such indicates that there is such-and-such inside you; but if that is not confirmed by the analysis of this-and-that, then it must be assumed that you have such-and-such... a floating kidney, chronic catarrh, or appendicitis.

\section{-The Death of Ivan Ilyich, Leo Tolstoy}

Teleology aside, there must be a molecular code that distinguishes these three categories of cell death to enable efferocytes to drive a specific effector response. As described above, this code requires more information than simply the molecular execution pathway. Ruslan Medzhitov predicted the presence of an invariant signal (such as phosphatidylserine [PtdSer]) together with a unique signature in the dying cell as a cell death code (Medzhitov 2008). Although PtdSer is a hallmark of cell death, the nature of the variable signal associated with the different causes of cell death remains poorly defined.

PtdSer is present in all eukaryotic cells and within the cell surface plasma membrane is asymmetrically distributed so that its vast majority faces the cytoplasm. This is achieved through phospholipid translocases that specifically move phospholipids from the outer to the inner leaflet of the lipid bilayer or vice versa in an ATP-dependent manner-flippases and floppases, respectively. Scramblases can negate this asymmetry by translocating phospholipids in both directions (Nagata et al. 2016). The exposure of PtdSer on the outer leaflet during apoptosis is the result of inhibition of flippases and activation of scramblases. Cleavage of flippases by apoptotic caspases render them inactive, reducing the ability to translocate PtdSer to the inner leaflet (Segawa et al. 2014). In contrast, cleavage of scramblases such as Xkr8 is essential for their activity (Suzuki et al. 2013). The net result is the increase in the amount of PtdSer on the surface of apoptotic cells (Fig. 2) and the activation of PtdSer-receptors (e.g., MERTK, TIM4, BAI1) on efferocytes leading to the clearance of the dead cell. A recent study has extended the function of exposed PtdSer as an "eat me" signal to necroptotic cells (Zargarian et al. 2017), yet whether this phospholipid functions as an universal "eat me" signal remains to be explored.

The variable molecular signatures of cell death represent the proxy of the elements that bring about death or, in other words, the reason for dying. As such, they should be associated with either type I, type II, or type III cell death. The most well-established variable signature is provided by damage-associated molecular patterns (DAMPs), which are classically associated with type III cell death. A series of DAMPs, such as alarmins and cytokines, are released during unscheduled cell death (Fig. 2). Although many DAMPs are commonly associated with type III cell death, some DAMPs can impart specificity to the effector response. For example, type III cell death can trigger a response characteristic of sterile injury wherein adaptive immune response is not engaged. When a specific pathogen is involved in causing cell death, the innate immune response is complemented with the induction of Th1, Th2, or Th17 adaptive immune responses. For example, intracellular lipopolysaccharide (LPS) directly activates caspase-11 in rodents or caspases- 4 and -5 in humans, which subsequently cleave and activate the pore-forming protein gasdermin D (GSDMD). The rupture of the plasma membrane leads to pore-induced intracellular traps (PITs) wherein live bacteria are contained in pyroptotic cell 


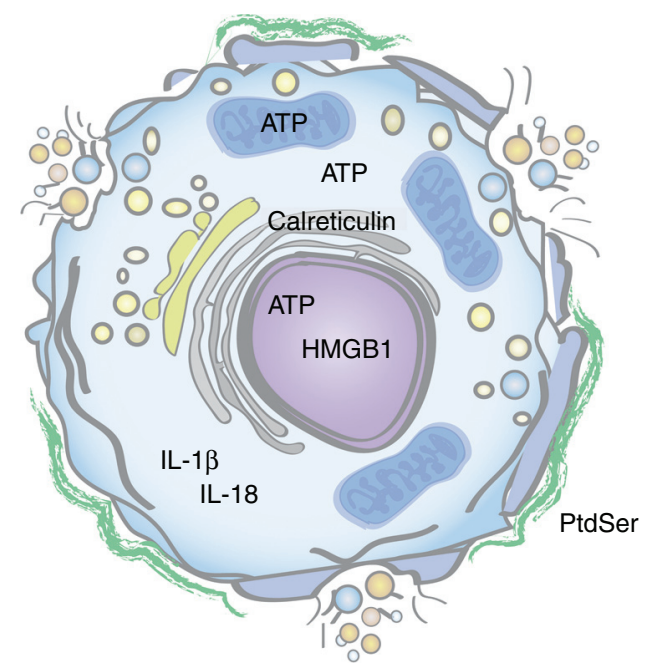

Figure 2. Invariant and unique molecular patterns associated with cell death. Phosphatidylserine ([PtdSer], indicated as green textured line) is a phospholipid found in all eukaryotic cells this is asymmetrically distributed in the plasma membrane of alive cells. Although PtdSer is enriched in the inner leaflet of live cells, it becomes invariantly exposed on the cell surface of apoptotic cells. Whether PtdSer is an universal molecular pattern of all cell death modalities remains unknown. Other molecular patterns of cell death are characterized by their distinct subcellular localization in live cells before their release when cells die. For example, calreticulin is found in the endoplasmic reticulum and HMGB1 in the nucleus. In contrast, ATP localization is less restricted, being present in mitochondria, the cytosol, and the nucleus. Molecular patterns associated with cell death can also be induced on specific cell death modalities. Activation of the inflammasome during pyroptosis leads to the production of interleukin (IL)-1 $\beta$ and IL-18.

corpses (Jorgensen et al. 2016a,b). The loss of $\mathrm{K}^{+}$ through GSDMD pores also leads to the activation of NLRP3 and the release of interleukin (IL)-1 $\beta$ and IL-18 (Rathinam et al. 2019). IL- $1 \beta$ and IL- 18 , together with eicosanoids, promote the recruitment of neutrophils and clearing of PITs. These DAMPs are also critical for the ensuing Th1/Th17 responses (Rathinam et al. 2019). In contrast, release of TSLP, IL-33, and IL-25 on injury to epithelial barriers leads to the the induction of type 2 immunity including Th2 adaptive immune response ( $\mathrm{Han}$ et al. 2017).
Alarmins can be found in different intracellular compartments (Fig. 2). The distinct subcellular localization of alarmins, for example, ATP in the cytosol, calreticulin in the endoplasmic reticulum (ER) and HMGB1 in the nucleus, may function as the basis for a temporal code in the progression of cell death. Apoptotic caspases activate the channel Pannexin I that allows the release of ATP while the plasma membrane is still intact, promoting the recruitment of phagocytes to the "death bed" (Elliott et al. 2009). This might be the first alarmin released in preparation of the impending cell death. Once released into the extracellular space, alarmins exert distinct functions from the ones associated with their intracellular localization. The intracellular metabolite ATP, not only induces the migration of phagocytes (Elliott et al. 2009) but at higher concentrations can also lead to activation of the inflammasome NLRP3 in the presence of pathogen-associated molecular patterns (PAMPs) (Ghiringhelli et al. 2009). In contrast, the translocation of ER-localized calreticulin or release of nuclear HMGB1 should require additional organelle damage that provides a time-delay mechanism for their release.

Not only the sequence of release of alarmins, but their integration with the timing of PtdSer exposure, may encode specific effector functions. Chemotherapeutic agents have been shown to promote the active translocation of calreticulin before PtdSer exposure, favoring the uptake of the corpse by dendritic cells (DCs) and thereby promoting an immunogenic response (Obeid et al. 2007; Panaretakis et al. 2009). However, when calreticulin is displayed as PtdSer is exposed, it potentiates the uptake of the dead cell by macrophages (Gardai et al. 2005) favoring an anti-inflammatory response. The signal integration between the receptors activated by the exposed/released DAMPs and the sensing of PtdSer remains to be explored.

Similarly, metabolites released during the process of cell death could reveal whether the cell is dying to preserve a function (type II) or dying as a result of injury (type III) and specify different effector functions. For example, the release of lactic acid from damaged skeletal muscle cells may instruct satellite cell proliferation and 
myogenesis or promote myoblast differentiation (Willkomm et al. 2014; Tsukamoto et al. 2018) In contrast, uric acid and cholesterol crystals, resulting from lytic cell death, induce inflammation through the NLRP3 inflammasome (Martinon et al. 2006; Duewell et al. 2010).

Can there be other forms of cell-intrinsic information indicating which cell is dying and why? It is conceivable that even the "identity" of the dead/dying cell may inform the efferocyte why the cell is dying. For example, the identity of a cell may predestine it to a favored mode of cell death. Terminally differentiated cells may prefer to die by means different from cycling cells. A terminally differentiated cell, such as a neuron or a cardiomyocyte, cannot be replaced easily unlike a fibroblast or an epithelial cell. At the same time, the neuron or cardiomyocyte is not at risk of transforming into a cancer cell unlike an epithelial or stromal cell. The identity of the dead cell may also be disclosed by the release of molecules unique to the cell type. For example, heart injury and cardiomyocyte death are associated with the release of the actin-associated cardiac troponins. Interestingly, the muscle actin-binding protein myosin II, was recently shown to potentiate the binding of F-actin released from necrotic cells to DNGR1 on DCs and promote cross-presentation of antigens (Schulz et al. 2018). Therefore, the cellular identity of a dying neuron or cardiomyocyte itself may specify type III cell death.

Apart from the death masks described above, additional information may also be encoded by when a cell dies. Although DNA damage leads to cell death, various inducers of DNA damage are known to arrest and subsequently kill cells at various phases of the cell cycle such as at the $G_{1}, S$, or $G_{2} / M$ checkpoints. Mitotic poisons kill cells through mitotic catastrophe in $\mathrm{M}$ phase. Other chemicals such as retinoic acid, 5-FU, and methylxanthine-derived drugs can lead to $G_{1}, S$, or $G_{2} / M$ arrest, respectively, and subsequent cell death (Shapiro and Harper 1999). $G_{1}, S$, or $G_{2} / M$ arrest are mediated by molecules that can be shared, but also include molecules that work at specific checkpoints. For example, p53 functions at the $G_{1}$ checkpoint, but $\mathrm{Nbs} 1$ and Chk1 function at the $\mathrm{S}$ checkpoint and BRCA1 at the $\mathrm{G}_{2} / \mathrm{M}$ checkpoint (Sancar et al. 2004). Whether this information is available to the efferocyte and whether it can inform the efferocyte of the cause of cell death remains entirely unknown.

\section{THE ENVIRONS OF CELL DEATH}

The word death is not pronounced in New York, in Paris, in London, because it burns the lips. The Mexican, in contrast, is familiar with death, jokes about it, caresses it, sleeps with it, celebrates it; it is one of his favorite toys and his most steadfast love. True, there is perhaps as much fear in his attitude as in that of others, but at least death is not hidden away; he looks at it face to face with impatience, disdain or irony.

\section{-El Laberinto de la Soledad y otras obras (The Labyrinth of Solitude and other works), Octavio Paz}

In keeping with the sentiment alluded to above, we postulate that environmental signals, in addition to the type of cell death, influence the funeral rites (Fig. 3). Changes in environmental signals can specify type I cell death to instruct the elimination of a function. In seasonally breeding male song birds, the levels of testosterone increase during the breeding period and the song center significantly increases in size. After mating, the levels of testosterone decline resulting in a wave of apoptosis (Thompson 2011). Similarly, sex hormones drive the hyperplasia of the pituitary and mammary glands during pregnancy and their decline postpartum and postlactation is associated with pituitary and mammary involution (Scheithauer et al. 1990; McNally and Stein 2017). Efferocytes are responsible for removal of these dead cells. Typically in adult vertebrates, efferocytosis is associated with proliferation and renewal or repair. Removal sans renewal or repair is seen primarily in development. Therefore, the responses to these dying cells in adults resemble those during development. It is intriguing to hypothesize that efferocytes exposed to sex hormones are reprogrammed to respond by solely removing the dead cells rather than triggering their replacement.

Environmental signals present during type II or type III cell death may be physical cues. For 


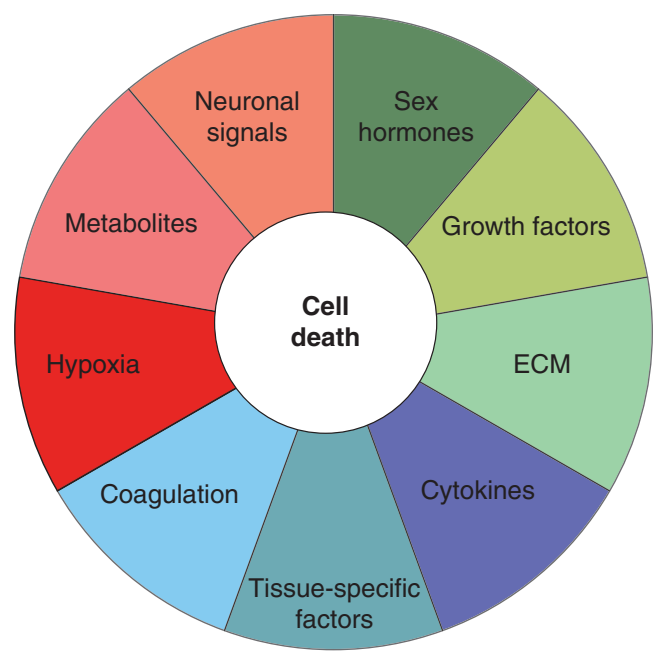

Figure 3. Environmental signals and cell death. A panoply of signals, spanning from hormones and cytokines to neurotransmitters, metabolites, and beyond can coexist with dead cells. The processing of cell death recognition together with distinct environmental signals contributes to the specification of the outcomes of cell death. ECM, Extracellular matrix.

example, loss of cell-cell contact owing to cell death or changes in the stiffness of the extracellular matrix may be an environmental signal sensed by the effectors. It has been described that cell-cell contacts and growth factors such as epidermal growth factor (EGF) establish a tunable system that guides cell-cycle decision making (Kim et al. 2009). A critical threshold of environmental EGF concentration defines the contact-uninhibited from contact-inhibited states of epithelial cells. Conversely, the strength of cell-cell contacts is proportional to the concentration of EGF required to drive cells into cell cycle. Matrix stiffening can reduce the threshold concentration of environmental EGF required to override contact inhibition (Kim and Asthagiri 2011). Perhaps local matrix stiffness or loss of cellular contacts are similarly integrated with the type of cell death to shape the transcriptional output of the efferocyte that responds to cell death. Even more common may be chemical signals. Clotting factors, oxygen concentration (hypoxia), or cytokines and metabolites produced by responding or bystander cells could inform on the cause of cell death insofar as to interpret it as type II or III cell death. We have previously shown that sensing apoptotic cells together with sensing the cytokine IL-4 enables macrophages to promote healing in the context of type III cell death (Bosurgi et al. 2017). In response to helminth infections, tissue-resident macrophages recruit neutrophils to the damaged site. Following the successful control of the pathogen, neutrophils die by apoptosis. The coincident detection of apoptotic neutrophils and the hallmark cytokine produced during helminth infections-IL-4-induces a tissue repair response in macrophages (Bosurgi et al. 2017). Of note, this response is distinct from that of type II, apoptotic death of aged neutrophils under physiological conditions. In the latter case, the response is the increase production of granulocyte colony-stimulating factor (G-CSF) to replenish the neutrophil pool (Furze and Rankin 2008). The shift in the response from induced proliferation of the lost cells to induction of tissue repair constitutes an example of how environmental cues, such as cytokines, can diversify the response to cell death.

Phagocytosis may also sometimes be restricted to a part of, rather than the whole cell. Such is the case of pruning of presynaptic axonal buttons by microglia during brain development, wherein PtdSer exposure is restricted to the membrane destined to be eaten. Local, environmental cues have been shown to modulate synaptic pruning. IL-33 was found to be expressed by synapse-associated astrocytes in the spinal cord and thalamus and to increase the engulfment of synapses by microglia (Vainchtein et al. 2018). The necessity for invoking a "third-party"-derived molecule for effective pruning of synapses underscores the functional integration of cells in the nervous system rather than a "private" conversation between the phagocyte and the cargo for physiological development of neuronal circuits.

The nature of the environmental signal might be also tissue-specific. Minutti et al. showed that surfactant protein A (SP-A) potentiates IL-4-induced polarization of lung macrophages in response to damage elicited by helminth infection (Minutti et al. 2017). In con- 
trast, $\mathrm{C} 1 \mathrm{q}$ was found to potentiate the repair response of macrophages induced by IL-4 in the liver after bacterial infection. This suggests that the integration of cell death sensing with the prevailing cytokine and tissue-specific environmental signals could specify tissue-specific responses. The distinct tissue repair responses adapted to the requirements of specific tissues is an important area of future investigations.

Type III cell death is associated with signature environmental signals. The clotting factor thrombin was recently shown to cleave and activate the cytokine IL- $1 \alpha$ in macrophages (Burzynski et al. 2019), leading to the infiltration of immune cells and subsequent wound healing. Hypoxia is also closely associated with an inflammatory state. Although vascular flow is increased during the onset of inflammation, inflamed areas are hypoxic. This is caused by higher interstitial pressure adversely affecting oxygen diffusion into the tissue and also because of increased oxygen consumption in the damaged tissue. Neutrophils increase their oxygen consumption during phagocytosis-a process termed "respiratory burst." This, in turn, can induce a transcriptional program associated with hypoxia in intestinal epithelial cells (Campbell et al. 2014). Hypoxia can also affect transcription factors (i.e., HIF $1 \alpha$ ), leading to the production of growth factors and promoting endothelial proliferation and growth (Semenza 2000; Apte et al. 2019). Similarly, lactic acid produced in the wound bed leads to the stabilization of HIF $1 \alpha$ and the expression of vascular endothelial growth factor (VEGF) by macrophages further contributing to angiogenesis (Constant et al. 2000). Of note, comparable responses underlie pathological angiogenesis that fuels the growth of tumors (Colegio et al. 2014). Thus, thrombin, hypoxia, and lactic acid operate in concert in the induction of tissue repair responses to unscheduled, type III cell death. Yet, how the response to clotting factors, hypoxia, and lactic acid is integrated with the sensing of dead cells remains unexplored.

Another interesting environmental correlate may be neuronal signals. On intestinal bacterial infection, the extrinsic sympathetic nervous system was shown to induce a tissue repair program in muscularis macrophages $(\mathrm{Ga}-$ banyi et al. 2016). Pain has both been positively, as well as negatively, correlated with wound healing. Some studies claim that pain enables improved wound healing, whereas others indicate that pain is detrimental to wound healing. The latter includes the recent characterization of a microdeletion in an FAAH pseudogene in a patient who shows pain and anxiety insensitivity, elevated amounts of anandamide in circulation, and accelerated skin wound healing (Habib et al. 2019). Macrophages express the anandamide receptors $\mathrm{CB}_{1}$ and $\mathrm{CB}_{2}$ (Mai et al. 2015) and may be the direct substrates of neuronal signal-induced wound repair.

\section{WHO CARES ABOUT THE DEAD CELL}

... it's the others who would live my death

- The Mandarins, Simone de Beauvoir

The macrophage has been front and center of cell death literature as the prime sensors and disposers of dead cells. Even so, evidence suggests that there may be functional redundancies between mononuclear phagocytes and other efferocytes, especially during development. For example, the germline genetic ablation of Csf1r, which encodes for the receptor involved in macrophage differentiation, leads to a significant reduction in the number of mononuclear phagocytes in both mice and rats (Dai et al. 2002; Pridans et al. 2018). However, the effects of microglial loss on brain development were less severe in the rat than in the mouse. Despite the absence of microglia, no major abnormalities were observed in the rat brain with the exception of enlargement of lateral ventricles (Pridans et al. 2018). In contrast, both species displayed severe abnormalities in teeth eruption, bone, and reproductive functions (Dai et al. 2002; Pridans et al. 2018). These results indicate that there are redundancies in efferocytosis although such redundancies might be tissue-specific across species. Interestingly, other cell types such as fibroblasts, epithelial cells, and endothelial cells also express efferocytosis receptors (Arandjelovic and Ravichandran 2015). Studies including Monks et al. (2005), Juncadella et al. 
C.V. Rothlin and S. Ghosh

(2013), and Mesa et al. (2015) show that epithelial cells can function as efferocytes.

Since many different cells can partake in the sensing and disposal of the dead cells, we propose that the effector function to cell death is, at least in part, determined by the identity of the sensor/efferocyte (Fig. 4). Furthermore, even macrophages resident in different tissues use distinct efferocytosis receptor repertoire and respond to efferocytosis through distinct transcriptional signatures (A-Gonzalez et al. 2017). Thus, the transcriptional program unleashed because of sensing/efferocytosis should depend on the cellular identity of the efferocyte and/or the identity of the efferocytosis receptors.

Dead/dying neurons are removed both during embryonic and postnatal development, as well as in adults. Theoretically, it is possible that the efferocytosis of dead/dying neurons is entrusted to different cell types in development and in adulthood. Alternatively, the efferocyte uses distinct efferocytosis receptors for disposal of the dead cells. Importantly, efferocytosis of embryonic and postnatal neurons during their programmed death culminates in a removal- only response and morphogenesis. It is likely that adult neurogenesis, in contrast, is associated with a counting mechanism mediated by efferocytes and a signal for replenishment as loss of the efferocytosis receptor MERTK in microglia leads to increased neural stem cell proliferation (Fourgeaud et al. 2016).

In keeping with the extraordinary diversity of cell death sensors, macrophages present themselves in several "avatars" (appear in different forms; the term "avatars" originates from the incarnations of Vishnu in different forms in different eras). Differentially polarized macrophages use distinct receptors for phagocytosis and the outcome of phagocytosis too can be quite different. Fc $\gamma$ RI-, Fc $\gamma$ RII-, and CD13-mediated phagocytosis were significantly increased in IL-10 polarized macrophages, compared with nonpolarized $\left(\mathrm{M}_{0}\right)$ macrophages (MendozaCoronel and Ortega 2017). Conversely, IL-4 polarization of macrophages enhanced the phagocytosis of Escherichia coli but not FcyRor CD13-mediated phagocytosis (MendozaCoronel and Ortega 2017). IFN- $\boldsymbol{\gamma}$-polarized macrophages and IL-4-polarized macrophages

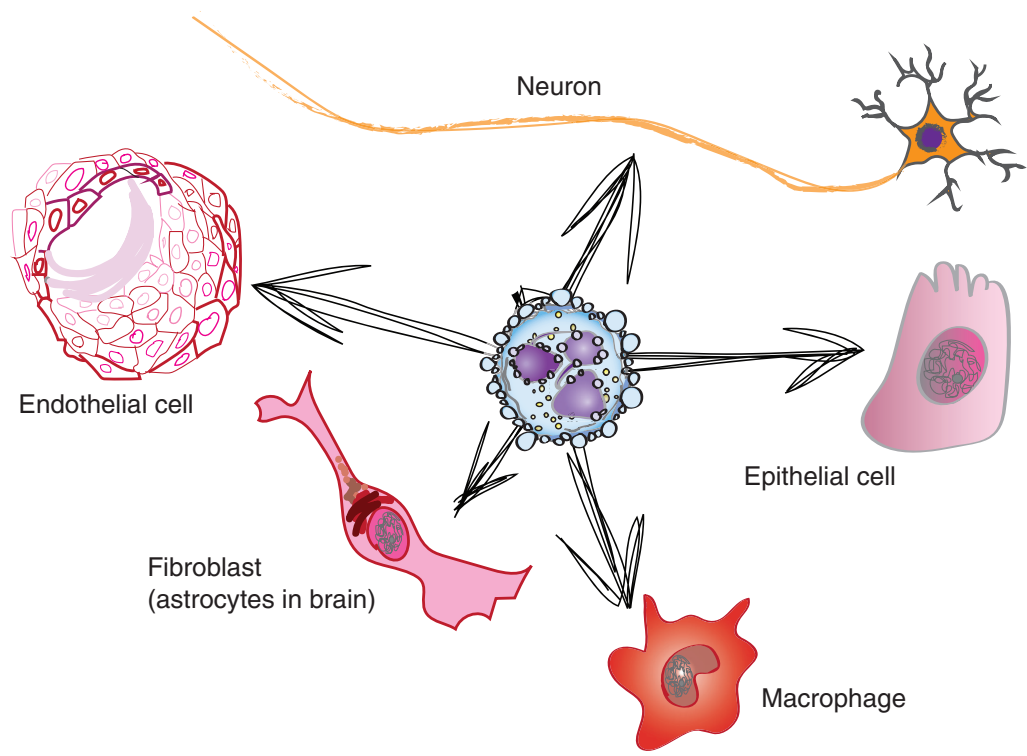

Figure 4. Who cares about dead cells? An array of different cells are endowed with the capacity to efferocytose or sense dead cells. The identity of the cellular sensors involved in the diverse tissues and contexts in which cells can die in part dictates the specific outcomes of the efferocytes that respond to dead cells. 
were both more efficient in the phagocytosis of Porphyromonas gingivalis, but only the IFN- $\gamma$ polarized macrophages were better able to kill the bacteria (Lam et al. 2016). Could it be that there is some specificity for a particular polarization of macrophages for efferocytosis? Could efferocytosis in differentially polarized macrophages or through different efferocytosis receptors encode distinct functional outcomes? Dexamethasone was shown to up-regulate MERTK-mediated uptake of dead cells in macrophages, whereas polyI:C up-regulated AXLmediated efferocytosis (Zagorska et al. 2014). How this is linked to function remains unclear.

Anticancer immunity may represent a function encoded by the specificity of phagocytes. Although DCs and macrophages are both avid phagocytes, DCs are better at antigen-presentation and in their ability to engage the adaptive immune system. Macrophages, although capable of presentation of foreign antigen on MHCII, are the professional phagocytes involved mostly in scavenging and disposal of type I cell death or for signaling proliferation during homeostatic removal of cells undergoing type II cell death. DCs, in contrast, are typically involved in the context of type III cell death. Therefore, the removal of dead cancer cells by DCs might be critical for generating an anticancer immune response, whereas macrophage-dependent clearance may abet immune escape. We speculate that both cell-intrinsic and environmental signals associated with type II cell death are involved in tumorigenesis and tumor progression. Tumors have been designated as "a wound that never heals." Elimination or blockade of these signals may be important in arresting the propagation of this "wound" that continuously signals for replenishment. Furthermore, triggering a response associated with type III cell death may be what is optimal for eliminating the tumor.

Finally, successful repair and "restitution ad integrum" may involve a coordinated sequence of cell death sensing by phagocytes. The sensing of endothelial cell death by platelets could trigger coagulation and hemostasis. This initial event is followed by inflammation and neutrophil recruitment. Neutrophils often die by a distinct cell death modality while fighting a pathogen-netosis. This changes as the pathogen is cleared and neutrophils continuing to arrive at the wound site die because of lack of growth factor by apoptosis. Macrophages clear the dead cells, including dead neutrophils. We have previously reported that recognition of apoptotic neutrophils by macrophages spurs macrophage polarization to a tissue-repair phenotype (Bosurgi et al. 2017). Finally, the fibroblasts themselves die to allow remodeling of the extracellular matrix and vasculature. As discussed before, epithelial and stromal cells also express cell death sensors. But how the sensing of cell death by these cells may lead to their differential functions during wound repair, such as in fibroblast proliferation and differentiation, epithelial proliferation, and re-epithelialization or angiogenesis, remains unclear. It is possible that aberrations in the sequential cell death recognition in an injured tissue are the basis of wound repair defects spanning from failure of wound closure or ulcers to abnormal growth/overgrowth of unwanted cell types or fibrosis.

\section{CONCLUDING REMARKS}

When you're standing on the crossroads that you cannot comprehend

Just remember that death is not the end -Death Is Not the End, Bob Dylan

In summary, cell death is a conserved feature of developmental remodeling/morphogenesis, tissue turnover/renewal, as well as injury/repair. Inappropriate effector responses to cell death can manifest as developmental defects, tissue degeneration, tumorigenesis and tumor progression, ulcerative damages, infections, fibrosis, and a host of other pathologies. We propose a simple cell death code categorized in a manner consistent with outcomes of cell death, namely, removal, renewal, and repair/regeneration. We also posit that the integration of information contained in a dying/dead cell, environmental signals associated with cell death and the identity of the responding phagocyte constitutes the molecular and cellular basis of this code. 
Understanding the fundamental principles guiding the response to cell death may allow modulation of the effector response to better engage physiological processes and to avoid/reduce pathological outcomes of cell death.

\section{ACKNOWLEDGMENTS}

We apologize to those whose work we were unable to cite because of space limitations. We thank Ruslan Medzhitov whose work, in part, has inspired this review. We thank Ed Miao for the Bob Dylan quote. This work was supported by grants from the National Institutes of Health (NIH-NIAID R01 AI089824 and NIH-NCI R01 CA212376) and the Kenneth Rainin Foundation. C.V.R is a Howard Hughes Medical Institute (HHMI) Faculty Scholar.

\section{REFERENCES}

A-Gonzalez N, Quintana JA, García-Silva S, Mazariegos M, González de la Aleja A, Nicolás-Ávila JA, Walter W, Adrover JM, Crainiciuc G, Kuchroo VK, et al. 2017. Phagocytosis imprints heterogeneity in tissue-resident macrophages. J Exp Med 214: 1281-1296. doi:10.1084/jem .20161375

Apte RS, Chen DS, Ferrara N. 2019. VEGF in signaling and disease: beyond discovery and development. Cell 176: 1248-1264. doi:10.1016/j.cell.2019.01.021

Arandjelovic S, Ravichandran KS. 2015. Phagocytosis of apoptotic cells in homeostasis. Nat Immunol 16: 907-917. doi:10.1038/ni.3253

Avino TA, Barger N, Vargas MV, Carlson EL, Amaral DG, Bauman MD, Schumann CM. 2018. Neuron numbers increase in the human amygdala from birth to adulthood, but not in autism. Proc Natl Acad Sci 115: 3710-3715. doi:10.1073/pnas.1801912115

Bosurgi L, Cao YG, Cabeza-Cabrerizo M, Tucci A, Hughes LD, Kong Y, Weinstein JS, Licona-Limon P, Schmid ET, Pelorosso F, et al. 2017. Macrophage function in tissue repair and remodeling requires IL-4 or IL-13 with apoptotic cells. Science 356: 1072-1076. doi:10.1126/science .aai8132

Burzynski LC, Humphry M, Pyrillou K, Wiggins KA, Chan JNE, Figg N, Kitt LL, Summers C, Tatham KC, Martin PB, et al. 2019. The coagulation and immune systems are directly linked through the activation of interleukin- $1 \alpha$ by thrombin. Immunity 50: 1033-1042.e6. doi:10.1016/j immuni.2019.03.003

Campbell EL, Bruyninckx WJ, Kelly CJ, Glover LE, McNamee EN, Bowers BE, Bayless AJ, Scully M, Saeedi BJ, Golden-Mason L, et al. 2014. Transmigrating neutrophils shape the mucosal microenvironment through localized oxygen depletion to influence resolution of inflammation. Immunity 40: 66-77. doi:10.1016/j.immuni.2013.11.020
Colegio OR, Chu NQ, Szabo AL, Chu T, Rhebergen AM, Jairam V, Cyrus N, Brokowski CE, Eisenbarth SC, Phillips GM, et al. 2014. Functional polarization of tumour-associated macrophages by tumour-derived lactic acid. Nature 513: 559-563. doi:10.1038/nature 13490

Constant JS, Feng JJ, Zabel DD, Yuan H, Suh DY, Scheuenstuhl H, Hunt TK, Hussain MZ. 2000. Lactate elicits vascular endothelial growth factor from macrophages: a possible alternative to hypoxia. Wound Repair Regen 8: 353360. doi:10.1111/j.1524-475X.2000.00353.x

Dai XM, Ryan GR, Hapel AJ, Dominguez MG, Russell RG, Kapp S, Sylvestre V, Stanley ER. 2002. Targeted disruption of the mouse colony-stimulating factor 1 receptor gene results in osteopetrosis, mononuclear phagocyte deficiency, increased primitive progenitor cell frequencies, and reproductive defects. Blood 99: 111-120. doi:10 $.1182 /$ blood.V99.1.111

Daley SR, Teh C, Hu DY, Strasser A, Gray DHD. 2017. Cell death and thymic tolerance. Immunol Rev 277: 9-20. doi:10.1111/imr.12532

Duewell P, Kono H, Rayner KJ, Sirois CM, Vladimer G, Bauernfeind FG, Abela GS, Franchi L, Nunez G, Schnurr $\mathrm{M}$, et al. 2010. NLRP3 inflammasomes are required for atherogenesis and activated by cholesterol crystals. Nature 464: 1357-1361. doi:10.1038/nature08938

Elliott MR, Chekeni FB, Trampont PC, Lazarowski ER, Kadl A, Walk SF, Park D, Woodson RI, Ostankovich M, Sharma P, et al. 2009. Nucleotides released by apoptotic cells act as a find-me signal to promote phagocytic clearance. Nature 461: 282-286. doi:10.1038/nature08296

Fourgeaud L, Través PG, Tufail Y, Leal-Bailey H, Lew ED, Burrola PG, Callaway P, Zagórska A, Rothlin CV, Nimmerjahn A, et al. 2016. TAM receptors regulate multiple features of microglial physiology. Nature 532: 240-244. doi:10.1038/nature17630

Furze RC, Rankin SM. 2008. The role of the bone marrow in neutrophil clearance under homeostatic conditions in the mouse. FASEB J 22: 3111-3119. doi:10.1096/fj.08-109876

Gabanyi I, Muller PA, Feighery L, Oliveira TY, Costa-Pinto FA, Mucida D. 2016. Neuro-immune interactions drive tissue programming in intestinal macrophages. Cell 164: 378-391. doi:10.1016/j.cell.2015.12.023

Galluzzi L, Vitale I, Aaronson SA, Abrams JM, Adam D, Agostinis P, Alnemri ES, Altucci L, Amelio I, Andrews DW, et al. 2018. Molecular mechanisms of cell death: recommendations of the nomenclature committee on cell death 2018. Cell Death Differ 25: 486-541. doi:10 .1038/s41418-017-0012-4

Gardai SJ, McPhillips KA, Frasch SC, Janssen WJ, Starefeldt A, Murphy-Ullrich JE, Bratton DL, Oldenborg PA, Michalak M, Henson PM. 2005. Cell-surface calreticulin initiates clearance of viable or apoptotic cells through transactivation of LRP on the phagocyte. Cell 123: 321-334. doi:10.1016/j.cell.2005.08.032

Ghiringhelli F, Apetoh L, Tesniere A, Aymeric L, Ma Y, Ortiz C, Vermaelen K, Panaretakis T, Mignot G, Ullrich E, et al. 2009. Activation of the NLRP3 inflammasome in dendritic cells induces IL-1 $\beta$-dependent adaptive immunity against tumors. Nat Med 15: 1170-1178. doi:10.1038/nm .2028

Golpon HA, Fadok VA, Taraseviciene-Stewart L, Scerbavicius R, Sauer C, Welte T, Henson PM, Voelkel NF. 2004. 
Life after corpse engulfment: phagocytosis of apoptotic cells leads to VEGF secretion and cell growth. FASEB J 18: 1716-1718. doi:10.1096/fj.04-1853fje

Habib AM, Okorokov AL, Hill MN, Bras JT, Lee MC, Li S, Gossage SJ, van Drimmelen M, Morena M, Houlden H, et al. 2019. Microdeletion in a FAAH pseudogene identified in a patient with high anandamide concentrations and pain insensitivity. $\mathrm{Br} J$ Anaesth 123: e249-e253. doi:10 $.1016 /$ j.bja.2019.02.019

Han H, Roan F, Ziegler SF. 2017. The atopic march: current insights into skin barrier dysfunction and epithelial cellderived cytokines. Immunol Rev 278: 116-130. doi:10 $.1111 / \mathrm{imr} .12546$

Hernández-Martínez R, Covarrubias L. 2011. Interdigital cell death function and regulation: new insights on an old programmed cell death model. Dev Growth Differ 53: 245-258. doi:10.1111/j.1440-169X.2010.01246.x

Jordan D, Hindocha S, Dhital M, Saleh M, Khan W. 2012. The epidemiology, genetics and future management of syndactyly. Open Orthop J 6: 14-27. doi:10.2174/1874 325001206010014

Jorgensen I, Lopez JP, Laufer SA, Miao EA. 2016a. IL-1 $\beta$, IL18 , and eicosanoids promote neutrophil recruitment to pore-induced intracellular traps following pyroptosis. Eur J Immunol 46: 2761-2766. doi:10.1002/eji.201646647

Jorgensen I, Zhang Y, Krantz BA, Miao EA. 2016b. Pyroptosis triggers pore-induced intracellular traps (PITs) that capture bacteria and lead to their clearance by efferocytosis. J Exp Med 213: 2113-2128. doi:10.1084/jem .20151613

Juncadella IJ, Kadl A, Sharma AK, Shim YM, HochreiterHufford A, Borish L, Ravichandran KS. 2013. Apoptotic cell clearance by bronchial epithelial cells critically influences airway inflammation. Nature 493: 547-551.

Kim JH, Asthagiri AR. 2011. Matrix stiffening sensitizes epithelial cells to EGF and enables the loss of contact inhibition of proliferation. J Cell Sci 124: 1280-1287. doi:10.1242/jcs.078394

Kim JH, Kushiro K, Graham NA, Asthagiri AR. 2009. Tunable interplay between epidermal growth factor and cellcell contact governs the spatial dynamics of epithelial growth. Proc Natl Acad Sci 106: 11149-11153. doi:10 .1073/pnas.0812651106

Kuhn HG. 2015. Control of cell survival in adult mammalian neurogenesis. Cold Spring Harb Perspect Biol 7: a018895. doi:10.1101/cshperspect.a018895

Lam RS, O’Brien-Simpson NM, Holden JA, Lenzo JC, Fong SB, Reynolds EC. 2016. Unprimed, M1 and M2 macrophages differentially interact with Porphyromonas gingivalis. PLoS ONE 11: e0158629. doi:10.1371/journal.pone .0158629

Mai P, Tian L, Yang L, Wang L, Yang L, Li L. 2015. Cannabinoid receptor 1 but not 2 mediates macrophage phagocytosis by $\mathrm{G}_{(\alpha) \mathrm{i} / \mathrm{o}} / \mathrm{RhoA} / \mathrm{ROCK}$ signaling pathway. J Cell Physiol 230: 1640-1650. doi:10.1002/jcp.24911

Martinon F, Pétrilli V, Mayor A, Tardivel A, Tschopp J. 2006. Gout-associated uric acid crystals activate the NALP3 inflammasome. Nature 440: 237-241. doi:10.1038/na ture 04516

McNally S, Stein T. 2017. Overview of mammary gland development: a comparison of mouse and human. Method Mol Biol 1501: 1-17. doi:10.1007/978-1-4939-6475-8_1
Medzhitov R. 2008. Origin and physiological roles of inflammation. Nature 454: 428-435. doi:10.1038/nature07201

Mendoza-Coronel E, Ortega E. 2017. Macrophage polarization modulates $\mathrm{F} c \gamma \mathrm{R}$ - and $\mathrm{CD} 13$-mediated phagocytosis and reactive oxygen species production, independently of receptor membrane expression. Front Immunol 8: 303. doi:10.3389/fimmu.2017.00303

Mesa KR, Rompolas P, Zito G, Myung P, Sun TY, Brown S, Gonzalez DG, Blagoev KB, Haberman AM, Greco V. 2015. Niche-induced cell death and epithelial phagocytosis regulate hair follicle stem cell pool. Nature 522: 94-97.

Minutti CM, Jackson-Jones LH, García-Fojeda B, Knipper JA, Sutherland TE, Logan N, Ringqvist E, Guillamat-Prats R, Ferenbach DA, Artigas A, et al. 2017. Local amplifiers of IL-4R $\alpha$-mediated macrophage activation promote repair in lung and liver. Science 356: 1076-1080. doi:10 $.1126 /$ science.aaj2067

Monks J, Rosner D, Geske FJ, Lehman L, Hanson L, Neville MC, Fadok VA. 2005. Epithelial cells as phagocytes: apoptotic epithelial cells are engulfed by mammary alveolar epithelial cells and repress inflammatory mediator release. Cell Death Differ 12: 107-114.

Morimoto K, Amano H, Sonoda F, Baba M, Senba M, Yoshimine H, Yamamoto H, Ii T, Oishi K, Nagatake T. 2001. Alveolar macrophages that phagocytose apoptotic neutrophils produce hepatocyte growth factor during bacterial pneumonia in mice. Am J Respir Cell Mol Biol 24: 608-615. doi:10.1165/ajrcmb.24.5.4292

Nagata S, Suzuki J, Segawa K, Fujii T. 2016. Exposure of phosphatidylserine on the cell surface. Cell Death Differ 23: 952-961. doi:10.1038/cdd.2016.7

Obeid M, Tesniere A, Ghiringhelli F, Fimia GM, Apetoh L, Perfettini JL, Castedo M, Mignot G, Panaretakis T, Casares N, et al. 2007. Calreticulin exposure dictates the immunogenicity of cancer cell death. Nat Med 13: 5461. doi:10.1038/nm1523

Panaretakis T, Kepp O, Brockmeier U, Tesniere A, Bjorklund AC, Chapman DC, Durchschlag M, Joza N, Pierron G, van Endert P, et al. 2009. Mechanisms of pre-apoptotic calreticulin exposure in immunogenic cell death. EMBO J 28: 578-590. doi:10.1038/emboj.2009.1

Pridans C, Raper A, Davis GM, Alves J, Sauter KA, Lefevre L, Regan T, Meek S, Sutherland L, Thomson AJ, et al. 2018. Pleiotropic impacts of macrophage and microglial deficiency on development in rats with targeted mutation of the Csf1r locus. J Immunol 201: 2683-2699. doi:10.4049/ jimmunol.1701783

Rathinam VAK, Zhao Y, Shao F. 2019. Innate immunity to intracellular LPS. Nat Immunol 20: 527-533. doi:10.1038/ s41590-019-0368-3

Reddien PW, Cameron S, Horvitz HR. 2001. Phagocytosis promotes programmed cell death in C. elegans. Nature 412: 198-202. doi:10.1038/35084096

Ryoo HD, Gorenc T, Steller H. 2004. Apoptotic cells can induce compensatory cell proliferation through the JNK and the Wingless signaling pathways. Dev Cell 7: 491-501. doi:10.1016/j.devcel.2004.08.019

Ryu JR, Hong CJ, Kim JY, Kim EK, Sun W, Yu SW. 2016. Control of adult neurogenesis by programmed cell death in the mammalian brain. Mol Brain 9: 43. doi:10.1186/ s13041-016-0224-4 
C.V. Rothlin and S. Ghosh

Sancar A, Lindsey-Boltz LA, Ünsal-Kaçmaz K, Linn S. 2004 Molecular mechanisms of mammalian DNA repair and the DNA damage checkpoints. Annu Rev Biochem 73: 39-85. doi:10.1146/annurev.biochem.73.011303.073723

Saunders JW Jr. 1966. Death in embryonic systems. Science 154: 604-612. doi:10.1126/science.154.3749.604

Scheithauer BW, Sano T, Kovacs KT, Young WF Jr, Ryan N, Randall RV. 1990. The pituitary gland in pregnancy: a clinicopathologic and immunohistochemical study of 69 cases. Mayo Clin Proc 65: 461-474. doi:10.1016/S00256196(12)60946-X

Schulz O, Hanč P, Böttcher JP, Hoogeboom R, Diebold SS, Tolar P, Reis ESC. 2018. Myosin II synergizes with F-actin to promote DNGR-1-dependent cross-presentation of dead cell-associated antigens. Cell Rep 24: 419-428. doi:10.1016/j.celrep.2018.06.038

Segawa K, Kurata S, Yanagihashi Y, Brummelkamp TR, Matsuda F, Nagata S. 2014. Caspase-mediated cleavage of phospholipid flippase for apoptotic phosphatidylserine exposure. Science 344: 1164-1168. doi:10.1126/science .1252809

Semenza GL. 2000. HIF-1: mediator of physiological and pathophysiological responses to hypoxia. J Appl Physio (1985) 88: 1474-1480. doi:10.1152/jappl.2000.88.4.1474

Shapiro GI, Harper JW. 1999. Anticancer drug targets: cell cycle and checkpoint control. J Clin Invest 104: 16451653. doi:10.1172/JCI9054

Suzanne M, Steller H. 2013. Shaping organisms with apoptosis. Cell Death Differ 20: 669-675. doi:10.1038/cdd .2013 .11

Suzuki J, Denning DP, Imanishi E, Horvitz HR, Nagata S. 2013. Xk-related protein 8 and CED-8 promote phosphatidylserine exposure in apoptotic cells. Science 341: 403406. doi: $10.1126 /$ science. 1236758

Thompson CK. 2011. Cell death and the song control system: a model for how sex steroid hormones regulate naturally-occurring neurodegeneration. Dev Growth Differ 53: 213-224. doi:10.1111/j.1440-169X.2011.01257.x
Tsukamoto S, Shibasaki A, Naka A, Saito H, Iida K. 2018. Lactate promotes myoblast differentiation and myotube hypertrophy via a pathway involving MyoD in vitro and enhances muscle regeneration in vivo. Int J Mol Sci 19: 3649. doi:10.3390/ijms19113649

Vainchtein ID, Chin G, Cho FS, Kelley KW, Miller JG, Chien EC, Liddelow SA, Nguyen PT, Nakao-Inoue H, Dorman LC, et al. 2018. Astrocyte-derived interleukin-33 promotes microglial synapse engulfment and neural circuit development. Science 359: 1269-1273. doi:10.1126/sci ence.aal3589

Whitman MC, Greer CA. 2009. Adult neurogenesis and the olfactory system. Prog Neurobiol 89: 162-175. doi:10 .1016/j.pneurobio.2009.07.003

Willkomm L, Schubert S, Jung R, Elsen M, Borde J, Gehlert S, Suhr F, Bloch W. 2014. Lactate regulates myogenesis in C2C12 myoblasts in vitro. Stem Cell Res 12: 742-753. doi:10.1016/j.scr.2014.03.004

Yeo W, Gautier J. 2004. Early neural cell death: dying to become neurons. Dev Biol 274: 233-244. doi:10.1016/j .ydbio.2004.07.026

Yokouchi Y, Sakiyama J, Kameda T, Iba H, Suzuki A, Ueno N, Kuroiwa A. 1996. BMP-2/-4 mediate programmed cell death in chicken limb buds. Development 122: 37253734 .

Zagorska A, Traves PG, Lew ED, Dransfield I, Lemke G. 2014. Diversification of TAM receptor tyrosine kinase function. Nat Immunol 15: 920-928. doi:10.1038/ni.2986

Zargarian S, Shlomovitz I, Erlich Z, Hourizadeh A, OfirBirin Y, Croker BA, Regev-Rudzki N, Edry-Botzer L, Gerlic M. 2017. Phosphatidylserine externalization, "necroptotic bodies" release, and phagocytosis during necroptosis. PLoS Biol 15: e2002711. doi:10.1371/journal.pbio .2002711

Zou H, Niswander L. 1996. Requirement for BMP signaling in interdigital apoptosis and scale formation. Science 272: 738-741. doi:10.1126/science.272.5262.738 


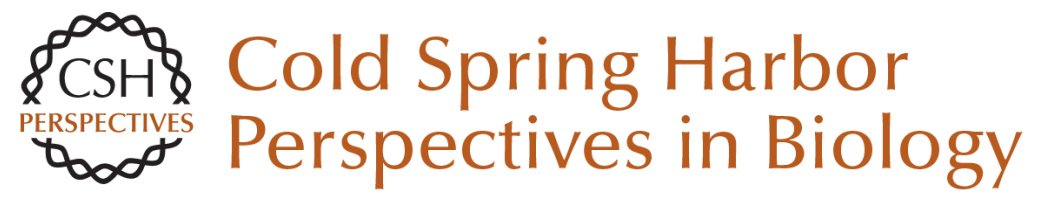

\section{Cracking the Cell Death Code}

Carla V. Rothlin and Sourav Ghosh

Cold Spring Harb Perspect Biol 2020; doi: 10.1101/cshperspect.a036343 originally published online September 23, 2019

\section{Subject Collection Cell Survival and Cell Death}

Programmed Cell Death in the Evolutionary Race against Bacterial Virulence Factors

Carolyn A. Lacey and Edward A. Miao

The Evolutionary Origins of Programmed Cell

Death Signaling

Kay Hofmann

Regulation of Cell Death and Immunity by XIAP Philipp J. Jost and Domagoj Vucic

Dysregulation of Cell Death in Human Chronic Inflammation

Yue Li, Christoph Klein and Daniel Kotlarz

Cell Death in Plant Immunity

Eugenia Pitsili, Ujjal J. Phukan and Nuria S. Coll

\section{Recent Insights on Inflammasomes, Gasdermin}

Pores, and Pyroptosis

Nathalia M. de Vasconcelos and Mohamed Lamkanfi

Phagocyte Responses to Cell Death in Flies Andrew J. Davidson and Will Wood

Mechanism and Regulation of

Gasdermin-Mediated Cell Death

Shiyu Xia, Louis Robert Hollingsworth IV and Hao Wu
Cell Death and Neurodegeneration Benjamin J. Andreone, Martin Larhammar and Joseph W. Lewcock

Death Receptors and Their Ligands in Inflammatory Disease and Cancer Alessandro Annibaldi and Henning Walczak

The Killer Pseudokinase Mixed Lineage Kinase Domain-Like Protein (MLKL) James M. Murphy

Neutrophil Extracellular Traps in Host Defense Sabrina Sofia Burgener and Kate Schroder

\section{Cell-Cycle Cross Talk with Caspases and Their} Substrates

Patrick Connolly, Irmina Garcia-Carpio and Andreas Villunger

Cracking the Cell Death Code Carla V. Rothlin and Sourav Ghosh

BAX, BAK, and BOK: A Coming of Age for the BCL-2 Family Effector Proteins Tudor Moldoveanu and Peter E. Czabotar

Multitasking Kinase RIPK1 Regulates Cell Death and Inflammation Kim Newton

For additional articles in this collection, see http://cshperspectives.cshlp.org/cgi/collection/

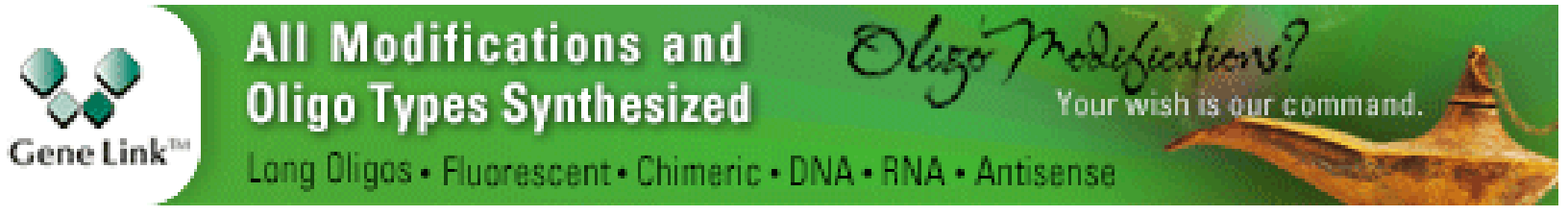


For additional articles in this collection, see http://cshperspectives.cshlp.org/cgi/collection/

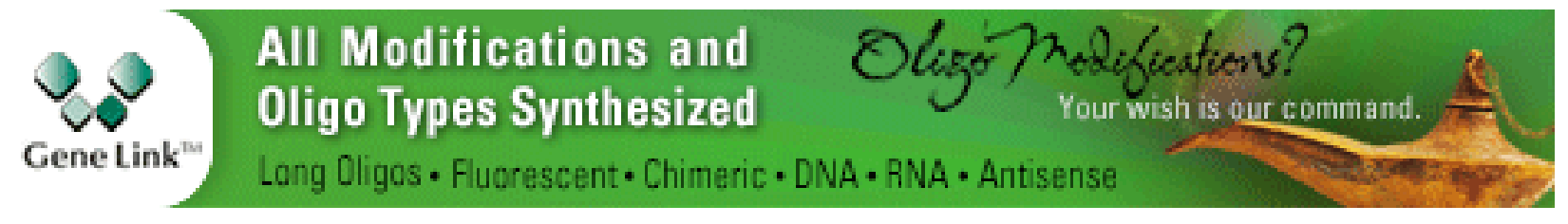

Copyright @ 2020 Cold Spring Harbor Laboratory Press; all rights reserved 